Euskal ikerketen aldizkaria | Revue d'études basques |

Revista de estudios vascos | Basque studies review

$9 \mid 2004$

Numéro IX

\title{
Euskarazko irakaskuntza Goierrin XVIII. mendeko bigarren erdian
}

Xabier Alberdi Lonbide et Alvaro Aragón Ruano

\section{OpenEdition}

\section{Journals}

Édition électronique

URL : http://journals.openedition.org/lapurdum/757

DOI : 10.4000/lapurdum.757

ISSN : 1965-0655

Éditeur

IKER

Édition imprimée

Date de publication : 1 novembre 2004

Pagination : 7-22

ISBN : 2-68781-376-X

ISSN : $1273-3830$

Référence électronique

Xabier Alberdi Lonbide eta Alvaro Aragón Ruano, « Euskarazko irakaskuntza Goierrin XVIII. mendeko bigarren erdian », Lapurdum [Linean], 9 | 2004, Sarean emana----an 01 mars 2009, kontsultatu 02 mai 2019. URL : http://journals.openedition.org/lapurdum/757 ; DOI : 10.4000/lapurdum.757 


\title{
Euskarazko irakaskuntza Goierrin XVIII. mendeko bigarren erdian
}

\author{
Xabier ALBERDI LONBIDE - Alvaro ARAGÓN RUANO \\ Euskal Herriko Unibertsitatea
}

Askotan esan ohi da euskarak ez zuela irakaskuntza publikoan tokirik izan XIX. eta, batez ere, XX. mendeak iritsi bitartean. Egia da Cardaberazek aipatzen zuela euskaraz irakastearen beharra kristau dotrina haurren artean zabaldu ahal izateko ${ }^{1}$, baina oraino ez da aurkitu inoiz, Aro Berrian zehar, euskaraz irakasten zenaren aztarna dokumentalik. Gure lan honen jomugak Gipuzkoako Protokoloen Agiritegian aurkitutako euskaraz irakasteari buruzko zenbait agiriren aurkezpena eta beren kokatze historikoa egiten saiatzea dira. Aitortu beharra dugu, historialariak izanik, aurkikuntza hau ez dela ikerketa filologiko baten emaitza, baizik eta gure ikerketa historiakoetan zehar egindakoa dela -aurreragoko beste batzuen antzera ${ }^{2}$, eta gure hizkuntza eta bere bilakaera historikoarekiko dugun interesak eta jakinminak bultzatu gaituztela pausu hau ematera.

Agiri hauek, XVIII. mendeko bigarren zatikoak, haurrei lehen hezkuntza emateko zenbait udalek maisuekin sinatutako kontratuak dira. Aurkitutako agiri hauek Gipuzkoako Goierri eskualdekoak dira. Probintziako gainontzeko eskualdeetan ere honelakorik eman ote zen edo jakiteko, eskualde bakoitzeko zenbait herri edo udaletako agiriak begiratu ditugu, inon antzekorik aurkitu gabe. Aipatutako Goierriko udalotan, gainera, frogatu ahal izan dugu XVIII. mendeko bigarren erdia baino lehen ez zela inoiz euskarazko irakaskuntzarik izan. Beste gai batzuk ikertzen ari ginela, begiratutako ehunka agiriren artean aipatutako kontratuak aurkitu genituen. Ondorioz, miaketa bat egitea erabaki genuen antzerako agiri gehiagoren bila, bai Gipuzkoako eskualde desberdinetako zenbait udaletako bai kronologia desberdineko dokumentazioa begiratuz. Honez gain, kontratuok aurkitu genituen udaletako agiriak begiratu genituen batik bat, aurreko edo ondorengo garaietan ere horrelakorik izan ote zen edo ez jakitearren. Adibidez, Ataunen 1696an eta 1768an sinatutako kontratuetan ez da euskaraz irakatsi behar zeneko aipamenik egiten ${ }^{3}$.

1 - Bere euskarazko gramatikari buruzko liburuaren sarreran zera zioen : “...Ora ̃ ba da, Iracurle Crista ua : bald in Quintilia noc, Marcelo bere adisquide cutunagatic, ta GETA a ren semea munduraco ondo acitceagatic, a mabi libru, aimbeste erregla, ta lecio banaca arguituaz atera bacituen: guc gure Jaungoico gucien Aita ma itea gatic, ta animen sa lva cioa ga tic cer ezdegu eguin bear? Ah! Ba tetic bestera a sco dijoa! Gure intencioa ren aldea n a renac cer icusi etzuen. Arc lurreraco, guc ceruraco: arc guiza arteraco, guc Ainguru arteraco umeac ondo a citcea na i degu : eta gucia, ez guretzat, ba icic Ja incoaren gloria ra co izan dedin..." (CARDABERAZ, A : Eusqueraren berri onac : eta ondo escribitceco, ondo iracurtceco, ta ondo itzegiteco erreglac. Iruñea : Libruguille Antonio Castilla-ren echean, 1761, 5 or.).

2 - ALBERDI LONBIDE, X. - RILOVA JERICÓ, C. : Iraganaren ahotsak. Euskararen erabilera Aro Modernoan Hondarribiko Udal Artxibategiko zenbait dokumentuen bidez. Irun : Luis de Uranzu Kultur Taldea, 1998. 3 - Gipuzkoako Protokoloen Agiritegi Orokorra (GPAO), PT IPT 1876, 83 aldea-84 iruntzia or. ; PT IPT 1926, 108 al.-109 ir. or. 
Miaketa honen ondorioz ziurtatu ahal izan dugu euskarazko irakaskuntza Goierriko udalerri batzuetan bakarrik eman zela, izan ere gainontzeko eskualdekoetan ez baitugu horrelakorik aurkitu; aldiz, hain ezagunak eta entzutetsuak diren euskaraz hitzegiteko debekuak eta haiek inposatzeko erabilitako eraztuna bezalako neurriak ohikoak izan ziren.

Aipatu irakasleak kontratatzeko agiriak XVIII. mendeko hizki humanistikoz idatziak daude. Gehienetan lau zatiz daude osatuak agiriok :

1. Agiria sinatzen den lekua eta data.

2. Agiriaren emaileen izenak.

3. Agiriaren edukiaren edo gaiaren azalpena.

4. Kontratuaren baldintza zerrenda :

4.1. Lanerako epea.

4.2. Maisuaren soldata.

4.3. Maisuaren bizilekua.

4.4. Maisuaren lantokia edo eskolaren egoitza.

4.5. Ikasleen gurasoek ordaindu beharreko dirusari kopurua.

4.6. Irakatsi beharreko ikasgaien zerrenda.

5. Bi aldeen adostasuna kontratua betetzeko eta, bete ezean, ezarri beharreko zigorrak eta isunak.

6. Eskribau eta lekukoen fidantza eta sinadurak.

\section{Lehen hezkuntzaren egoera orokorra aro berrian zehar}

Historialarion artean gauza jakina da Aro Berrian zehar Gipuzkoako erakundeek gaztelaniaren ezagutza sutsuki bultzatu zutela, nahiz eta oraindik zenbaiten artean harridura sortzen duela dirudien ${ }^{4}$. 1696an argitaratutako Gipuzkoako Foruek udaletako alkate izatera iristeko, besteak beste, irakurtzen eta idazten -gaztelaniaz suposatzen da- jakitera behartzen zuten ${ }^{5}$. Noski, kulturaren arloko baldintza honen bidez eta ekonomiaren arloko beste zenbait baldintzen bidez, Gipuzkoako udaletako eta Probintziako erakunde politikoak lurjabe eta merkatari handiz osatutako elite baten eskuetan geratu ziren. Izan ere, gutxiengo aberats batek bakarrik ordain baitzitzazkeen haurren ikasketek zekartzaten gastuak. Elite honetako kideentzat ezinbestekoa gertatzen zen erdarazko -gaztelaniazko, gaskoizko eta behar izanez gero latinezko edo frantsesezko- hezkuntza, Euskal Herriko lurraldeetatik kanpo erregearen eta elizaren agindupeko karguetara iritsi

4 - Adibidez, 1998-ko lan batean Azpiazu Elorzak zioen : “...Tradicionalmente se ha considerado al Pa ís Vasco como un pueblo iletrado que se empeñaba en mantenerse aferrado a una lengua sin a penas tradición litera ria escrita. A pesar de este estereotipo, a todas luces injusto, existen muestra sehacientes de la enorme preocupación de instituciones y particula res pa ra proporciona r a los jóvenes una oportunidad pa ra acceder a la instrucción..." (AZPIAZU ELORZA, J.A : "Las escuelas en el País Vasco a principios de la Edad Moderna. El interés por la enseñanza por parte de instituciones y particulares", Vasconia, 27 (1998), 148 or.).

5 - Gipuzkoako Foruetako III. tituloko XX. kapituloan biltzen den arau hau, 1573an eman zuen erregeak: "Por quanto en esta Provincia, Poblaciones, Alcaldias y Valles de ella, se hazen las elecciones del gobierno de la Republica añalmente, en hombres nobles, Hijosdalgo, limpios de toda mala raza, y se han experimentado grandes daños, è inconvenientes, de que en los pueblos se huviessen elegido sugetos, que no supiessen leer, y escribir, para el exercicio de Alcaldes Ordinarios, y de la Hermandad, y conviene mucho el obviarlos, y escusarlos en lo futuro. Ordenamos, y mandamos, que a hora y de a quí adelante, quando se hiciere eleccion de los oficios de los Concejos, se provea, de manera que los Alcaldes Ordina rios, é de la Hermandad, que se huvieren de elegir en todos los pueblos de esta Provincia, que tuvieren, mero, mixto imperio, sepan leer, y escribir, y que no se elijan para los tales oficios los que no supieren leer, y escribir..." (NUEVA RECOPILACIÓN de los Fueros, privilegios, buenos usos y costumbres, leyes y ordenanzas de la muy Noble y muy Leal Provincia de Guipuzcoa. Tolosa : Bernardo de Ugarte impresor de la misma Provincia, 1696, 60-61 or.). 
ahal izateko, nola Penintsulako aginte erakundetan hala Ameriketako kolonietako aginte eta ekonomia erakundetan ere.

Gertakari hau ez da Euskal Herriko fenomeno hutsa, ez eta gurean bezala bi hizkuntza edo gehiago elkarbizitzen ziren lekuetara mugatzen ere ; Aro Berrian zehar Europa osoan lekuan lekuko eliteen eta herri mailako kulturaren arteko sakabanatzea gertatu zen. Ekonomia, gizarte eta politika arloetan goi mailako kideak beren buruak herri xumearekiko behin betiko bereiztearren "goi mailako" kultura letradun, jantzi, fin eta esklusibista bat garatu zuten. Herri xumeak Erdi Arotik jasotako kultura, ohitura eta pentsamoldeekin jarraitu zuen. Berehala, ordea, beren botere ekonomiko eta politikoa sendotu ahal izateko elite horietako kideak ohartu ziren herri xumearen kultura birmoldatu eta egokitu egin behar zutela beren nahierara. Erlijio protestantedun lurraldeetan, adibidez, Biblia tokian-tokiko hizkuntzetara itzultzeari ekin zioten ${ }^{6}$. Euskal Herriari dagokionez hor dugu Joanes de Leizarragaren Itun Berriaren euskararako itzulpena, 1571an Nafarroako Joana III.a erregina protestantearen aginduz argitara emana. Itzulpengintza honen helburua herri xumearen artean Bibliako edukinak ulergarriro zabaltzea zen, horrela erlijio protestantearen aldeko bihur zitezen. Katolikoek ere laister erantzun zuten Trentoko Kontzilioan herriari dotrina tokian tokiko hizkuntzetan erakustea aginduz.

Bi gertakariok, hau da, batetik elitearen eta herri xumearen kulturaren arteko banaketa eta bestetik kultura herrikoi birmoldatu baten eraikuntza, Aro Berriko mendeetan zehar emeki-emeki garatu ziren, XVIII. mendean burutuz. Azken mende honetan bi kulturen arteko banaketa erabatekoa izatera iritsi zen eta ondorioz kultura herrikoi birmoldatuaren ezarketa ere inoiz baino sutsuago bultzatu zuten eliteko agintari eta elizgizonek. Gipuzkoako lehen hezkuntzari dagokionez, aintzinean aipatu denez, XVI, XVII eta XVIII. mendeetan beti gaztelaniaz ematen zen, elite horretako haurrak gazte-gaztetatik hizkuntza horretan aritzen ikas zezaten, gero bertako aginte postuetara eta kanpokoetara iritsi ahal izateko. Euskararen erabileraren nagusigoaren lekuko, helburu hau lortzeko udal agintariek kontratatutako maisuek bere ikasleei bai eskolan bai eskolatik kanpo euskaraz hitzegitea debekatu beharrean izaten ziren, aurkakoa egiten zutenei zigorrak ezarriz. Adibideak ugariak dira.

Errenterian, Pasaiako kaian kokatutako merkataritza eta industria nagusi ziren udalerrian, 1763an sinatutako irakasle kontratuak zioen: "...que les haia de enseñar a los muchachos que asistieren a el, a leer, escribir, contar y Doctrina Christiana, Ytroitos (sic) y Romance, dandoles para ello los acusadores y palillos que combegan para maior cuidado y vigilancia, de manera que dichos muchachos dentro de la escuela y fuera de ella, en las plazas y calles no haian de hablar vascuenze, sino castella no, unos con otros poniendoles para ello penas, a cusadores y palillos..."

Mende erdi bat lehenago, 1728an, Errenteriatik oso gertu dagoen Oiartzunen, aldi berean nekazal eta industrial girokoa den udalerrian ere ikasleei euskaraz hitzegitea galarazten zitzaien ${ }^{8}$. Baina zeharo nekazal girokoak edo arrantzale girokoak ziren udalerrietan ere ikasleen artean euskaraz aritzeko galerazpenak ere berdinak ziren. Honela, Aian, Oria eta Urola ibarren artean kokatzen den nekazal herrian, 1763an sinatutako irakasle kontratuan zera aipatzen da: "...que tengan assi mismo cuidado para que se enseñen y insttruian en la Lengua Castella na prohiviendo que enttre si en

6 - BURKE, P. : La cultura popular en la Europa moderna. Madrid : Alianza editorial, 1991

7 - GPAO, 3/2560, 123 al.-126 ir. or

8 - GPAO, $3 / 2203,24$ al.-31 ir. or. 
la escuela y fuera hablen la Bascongada imponiendo algun casttigo en casso de no observar estta prohivicion..." ${ }^{\prime 9}$. Antzera, ondoko Zarautz nekazal eta arrantzale udalerrian 1773ko kontratuan zioten : "...que ha ia de usa r con los chicos del a nillo para que hablen siempre castella no..."10.

Euskaraz besterik ez zekien eta gehiengo zabala osatzen zuen herri xumearen dotrina ikasketak, aldiz, lekuan lekuko apaiz eta elizgizonen eskuetan geratu ziren, pulpitotik euskaraz esandako irakatsietara murrizten zirelarik. XVIII. mendean, ordea, bi prozesuok kolapso egoerara arriskutsuki gerturatu ziren, izan ere, erderaz bakarrik ikasitako elite horretako kideen eta, batez ere, elizgizonen euskara jakintza eta erabilera maila zeharo urritua eta zabartua izatera iritsi baitzen. Kontuan izan behar da elite horretako kideek gazteleraren herri xumearengandik bereizteko erabiltzen zutela, baina erabilera honek XVIII. mendean beren bereiztu nahi horretan euskara gutxiesteraino iritsi ziren, gaztelera jende ikasi, aberats eta finaren hizkuntza zela pentsatuz eta, aldiz, euskara baserritar, pobre eta ezjakinena ${ }^{11}$. Ondorioz dotrinaren irakaskuntza herri xumearengan behar bezala bermatzeko, aurrerago ikusiko dugunez, elizgizonen artean erreakzio moduko bat hasi zen beren euskara maila hobetzeko. Erreakzio hau gainera gutxienez Goierriko zenbait herrietako udal agintariek ere bereganatu zuten euskarazko lehen hezkuntza bultzatuz gainontzeko udaletan ohikoa zenaren aurka.

\section{Dotrinaren irakaskuntzaren arazoa XVI eta XVIII. mendeen artean}

Gai honen ezagupenerako benetan erabakigarriak dira Iruñeako Artzapezpikutegiko agiritegian gordetzen diren Gipuzkoako Artzapez-barruti Txikiko agiri judizialak. Artzapez-barruti honek XVI. menderarte Baionako elizbarrutikoak izan ziren lurraldeak biltzen zituen, bere egoitza Hondarribian kokatua zegoelarik. Barruti hau Gipuzkoaren, Lapurdiren eta Nafarroaren arteko mugan, hau da Espainiako eta Frantziako estatuen mugan, egoteak garrantzi berezia demaio agiri sorta honi, izan ere, estatu eta aginte erakunde desberdinek bultzaturiko kultur politika desberdinak eta lurralde horiek guztietako eragin kultural desberdinak elkar ukitzen diren gunea baita. Beraz ikertu nahi diren gertakariok eta prozesuok berebiziko indarra hartzen duten gunea da, historialarion mesederako.

Goraxeago aipatu dugun kultura herrikoaren, hau da, gizarteko elitetik at zegoen gehiengoaren ofiziala ez zen kulturaren eraberriketa edo birmoldaketa elizgizonek zuzendua izan zen Europa osoan. Katolikoen artean Trentoko Kontzilioak 1562 eta 1563 an agindutako zenbait dekretuk kultura herrikoi horren birmoldaketa bultzatzen zuten. Helburu nagusia Erreforma Protestantearen mugaketa izanik, birmoldaketa horrek herri mailako erlijiotasunaren eraldaketa bultzatu zuen, zenbait erritu, jokabide eta festa erlijioso debekatuz, sakratuaren eta profanoaren arteko mugak zehaztuz. Aldi berean kristau moralaren aurkakoak gerta zitezkeen zenbait jokabide profanoen galarazpena lortzen ere saiatu ziren ${ }^{12}$.

9 - GPAO, 2/1393, 108 al. - 109 ir. or.

10 - GPAO, 2/1841, 228 al. - 230 ir. or.

11 - Aita Larramendik sutsuki gaitzetsi zituen pentsakera hau zuten elizgizonak: “...Ocasiones hay en que no debe predicarse en vascuence o en la lengua común de todos los oyentes, y es en aquellos sermones cuyos asuntos miran a los que mandan, dirigen y gobiernan, y no son para el común de los oyentes, ni éstos es razón que sepan cuán mal gobernados están y qué pecados cometen en su gobierno los que mandan, a menos que no ha ya otro camino para su enmienda que en sonroja rlos en público y con todo el común..." (LARRAMENDI, M. : Corografía o descripción general de la muy noble y muy leal Provincia de Guipúzcoa. Donostia : Sociedad Guipuzcoana de Ediciones y Publicaciones, 1982, 289 or.).

12 - BURKE, P. : La cultura popula r..., op.cit., 20-22, 29, 296-315, 331-341 eta 381-382 or. 
Gipuzkoako Artzapez-barruti Txikiari dagokionez ere kultura herrikoiaren birmoldaketa hau argi eta garbi bultzatu zuten bertako agintari eta elizgizonek. Herritar xumeen ohitura eta jokabide moral eta erlijiosoak eraberritzeko, bekatuaren jazarpenaz gain -adibidez sorginkeriaren eta erlijio protestantearen aurkakoa $^{13}$-, hiru motatako neurriak hartu zituzten : festa eta errituen birmoldaketa -alardeak, prozesioak eta antzerako festa berrien sorrera-, sozializazio erlijioso mota berrien sorkuntza -kofradia eta anaidi eta kongregazio erlijioso berrien sorrera- eta batez ere pastoralgintza. Protestanteen artean Biblia herri-hizkuntzetara itzultzea zabaldu zen bitartean -euskal protestanteen artean lehenago aipatu da Leizarragaren $1571 \mathrm{ko}$ Itun Berriaren itzulpena, katolikoen artean zenbait elizkizunetan herri-hizkuntzen erabilera bultzatu zen Trentoko Kontzilioaz geroztik. Elizkizun desberdinei dagokienez, dotrina katolikoa herritar xumeen artean zabaltzeko eta indartzeko eta haien pentsakerak beren nahierara moldarazteko, denetan eraginkorrenak herri-hizkuntzan egindako aitortza eta predikazioa ziren.

Herritar xumeen adimen landugabeetan predikulari edo sermolariek zuten eragin handiaz jabeturik, Hondarribiako agintariek ingurutako komentuetako sermolari entzutetsuak kontratatzen zituzten urtero. Sermolari hauen lana liturgia katolikoko data esanguratsuetan biltzen zen, adibidez Inauterietan eta Aste Santuan, herri ohitura moral zuzenak sustatzeko ; izan ere jai horietan oso ohikoak baitziren jan eta edaneko edo sexuarekin zerikusia zuteneko "gehiegikeriak" herritarren artean. Bertako edo kanpoko sermolariek erabiltzen zuten hizkuntza euskara izaten zen, hizkuntza hau besterik ez zekien gehiengoaren artean dotrina katolikoaren edukiak eta zentzapen morala behar bezala finkarazteko.

1615ean Garizumako sermoien inguruko hauzi bat gertatu zen Hondarribiako udalbatzaren eta bikarioaren artean. Garizumako igandetarako kanpoko sermolari bat kontratatzeak sortzen zituen gastuak saihestu nahirik, lan hori bertako bikarioa zen on Gabriel de Alberrok bere gain har zezan saiatu zen udalbatza. Hartarako, aipatutako auzia hasi zuen bikarioaren aurka, gaztelaniaz predikatu nahi ez zuela leporatuz. Udalbatzak bikarioa salatu zuen Iruñeako Artzapezpikutegiko Auzitegian esanaz: "...siendo cargo y obligacion de la dicha vicaria el dar sermon todos los domingos de la quaresma, ma ñana y tarde, en la dicha yglesia, con haversele pedido y encargado por la dicha villa que, assi como havian de ser en basquence y se a costumbrado predicar, el sermon de la mañana fuesse en romançe por el grande a uditorio que concurre en la dicha yglessia de personas que no saven ni entienden la lengoa bascongada como son el teniente de Capitan General, capitanes hordinarios, entretenidos, contadores, pagadores, soldados y otros ministros de su magestad, y que no havia querido complaçer en ello siendo ygual el travajo y tan en provecho de las almas el saver y entender la decla raçion del sancto evangelio y que por este respecto los dichos capitanes y ministros de su magestad se hallavan desconsolados, pidiendo y suplicandonos proveyessemos en el casso de devido remedio, y por nos visto su pedimiento y que lo que se pretende es el a provechamiento

13 - Hondarribian eta inguruetan burututako sorginkeria eta heresiaren jazarpenaz ikusi : ARZADÚN, J.A : "Las brujas de Fuenterrabía. Proceso del siglo XVII, el 6 de mayo de 1611 en Fuenterrabía", RIEV, 3 (1909) ; CARO BAROJA, J. : “Las brujas de Fuenterrabía (1611)”, Revista de dialectología y de tradiciones populares, 3 (1947); Idem : Brujería vasca. San Sebastián : Txertoa, 1985, 244-256 or. ; Idem : Las brujas y su mundo. Madrid : Alianza, 1986, 241 or. ; RILOVA JERICÓ, C. : "Brujería en la comerca del Bidasoa. El problema de la incredulidad en el siglo XVIII", Vasconia, 29 (1999) ; Idem : "De nuevo sobre el tema de la brujería. El problema de la incredulidad en el siglo XVIII", Historia Social, 38 (2000) ; Idem : "La última caza de brujas. En el nombre de Dios y de la Ilustración. La ciudad de San Sebastián en las navidades de 1818", Boletín de Estudios Históricos sobre San Sebastián, 35 (2001) ; Idem : "Las últimas brujas de Europa. Acusaciones de brujería en el País Vasco durante los siglos XVIII y XIX", Va sconia, 32 (2002). 
de las almas y aumento de la sancta fee catholica a que todos devemos ocurrir, y en particular siendo como es la dicha villa frontera al reyno de Francia a donde concurre jente de diversas naciones, por esta y el consuelo de los oyentes por tenor de la pressente le exortamos, requerimos y mandamos que siendo assi que tiene obligacion de dar dos sermones todos los domingos de la quaresma los haga y predique es a saver por la mañana en romance y a la tarde en basquence para que pueda saver y entender todo el a uditorio que acudiere y concurriere..." ${ }^{14}$.

Hondarribiako bikarioak ukatu egin zituen salaketok, esanaz udalbatzak benetan nahi zuena garizumako igandetarako sermolariak kontratzeak sortzen zizkion gastuak ekiditea zela. Zioenez, ordurarte udalak kontratatutako sermolari horiek pazko igandeko goizetan predikatzen omen zuten, gehienetan euskaraz, behin edo behin gaztelaniaz egiten bazuten ere. Are gehiago, zioen "...que yo no esto y obliga do en rrazon de la dicha mi vicaria a predicar los dichos domingos de quaresma mas de tan solo un sermon por las tardes despues de acabadas las bisperas y el tal en basquenze por ser la lengua materna y hordinaria de la dicha villa como lo hazia e hizo el bachiller don Pedro de Çuloaga, vicario que fue de la dicha yglessia mi anteçessor en todo el tiempo que lo fue, que es de quarenta a ños a esta parte por lo qual es en agrabio mio y de los demas vicarios mis subcessores...". Beraz, arazoa ez zen bikarioak gaztelaniaz predikatzerik nahi ez izatea baizik eta ez zegoela prest egun berdinean bi semoi ematera. Bere ustez sermoi bakarra eman behar zuen, eta bera euskaraz, hau baitzen gehiengoaren hizkuntza, eta ironikoki ohartarazten zuen "...alguna vez, como lo an alegado los del dicho gobierno, vienen a esta dicha villa alguna gente francessa y a y mas en ocassion de que en la dicha yglesia // (9. ir.or.) aya sermones; es la tal gente vasca que, por maravilla, ninguno de ellos saben ni entienden romançe sino vasquençe.

10. Yttem a si bien entre la gente de guerra que reside en la dicha villa que seran al pie de duçientos y ochenta hombres a lo mas, casi todos ellos son vascongados, la mayor parte de ellos naturales de la dicha villa, asi hombres como mugeres, marineros y los que viven en la s ca serias de ella no entienden otra lengua por que es su lenguaje natural el vascongado y lo entienden tanbien la demas gente prinçipal de la dicha villa"15.

Hondarribiako bikarioak argi eta garbi ikusten zuen ez zela bidezko sermoiak euskaraz ematen uztea, izan ere bertako auzo gehienek ez baitzuten besterik hitzegiten eta hiriko eliteko kide eta guarnizioko militar gehienak ere ulertzen zuten. Gainera, frogatua zuen sermoiak euskaraz egitean elizara zetozen eliztar kopurua nabarmen igotzen zela, izan ere Lapurditik ere jende ugari gerturatzen baitzen entzutera. Beraz, euskaraz predikatzeak dotrinaren eta moral katolikoaren zabalkunde handiagoa zekarrela zioen bikarioak, eta ez bakarrik hondarribitarren artean, baita Lapurdiko biztanleen artean ere, hau da garai hartan erlijio protestantearen kutsadura arriskuan bizi ziren lurralde bateko biztanleen artean.

Ondorengo mendeetan ere biztanleriaren ia gehiengo osoak euskara ulertzen eta hitzegiten jarraitu zuen, baina elebidunen kopurua igo egin zen, euskaraz besterik ez zekitenena txikiagotuz zihoala. Are gehiago gaztelaniaz besterik ez zekitenen kopurua ere handitu egin zen, hirietako eliteko kideen artean behintzat. Egoera honen lekuko ona 1744an Iruñako Elizbarrutiko Epaitegian hasitako beste auzi bat dugu. Nafarroako Narbarte herrikoa zen on Pedro Joseph de Zurbano presbiteroak

14 - Iruñeako Elizbarrutiko Agiritegia (IEA), Ollo, c.671 - n 33.

15 - IEA, Ollo, c.671 - n 33. 
hasi zuen auzia egungo Soria probintziako Ágreda herrikoa zen on Joseph de Estever presbiterioari Hondarribiako parrokian eliz-onura bat eman ez ziezaioten. Salatzaileak eliz-onura berari eman behar zitzaiola uste zuen, aldarrikatuz bere aurkaria jatorriz ez zela Iruñeako elizbarrutikoa eta ez zuela ulertzen "...el ydioma bascongado y enttenderlo mi partte quien por estte motivo podra tambien hacer maior servicio en dicha iglesia..." ${ }^{\prime \prime 6}$.

On Joseph de Esteverrek, salatutako presbiteroak, aldiz, zioen guztia bere aurkariak zion enbidiaren ondorioa zela, Hondarribian zortzi urte baino gehiago zeramazkienez bizitzen ezin ziezaieketela atzerritar bat balitz bezala tratatu eta “...a unque la contraria logre como supone la ynteligencia de la lengua vascongada no es qualidad prela tiba pues en dicha ziudad ygualmente se abla en la castellana y siempre se predica en esta misma ydioma y en el mismo se enseña a leer y escribir..."17. Auzi honetan ikusten denez, XVIII. mendearen erdi aldera Hondarribiako egoera linguistikoa asko aldatu zen aurreko mendean zegoenaren aldean. Oraindik ia gehiengo osoa euskaldun izaten jarraitzen bazuen ere, gaztelaniaz zekitenen kopurua asko handitu zen, batez ere agintari eta elizgizonen artean. Are gehiago, auzi honetan ikusten denez eliztarrei fedearen dotrinaren edukiak emateko elizgizonek euskaraz jakin beharra ez zen dagoeneko hain ezinbestekoa. Horrela uste zuten, behinik behin, Hondarribiako eliz kabildoko kideek, izan ere euskaraz hitzegiten ikasteko beharrik gabe hirian zortzi urte baino gehiago zeramazkien on Joseph de Esteverreri eliz-onura emateko inolako zalantzarik ez baitzuten izan. Hauzi honen epaia ere aldaketa hauen erakusgarri garbia dugu, on Josephek euskaraz ez jakitea ez baizuten inolaz ere oztopo bezala ikusten eliz-onuraren ematea berresteko.

XVIII. mendeko erdialdera Hondarribia bezalako udal euskaldun batean euskaraz ez zekien apaiz bat inolako arazorik gabe bizitzeak, dagoeneko zenbait giza inguru hiritarretan euskaraz jakitea ez zela ezinbestekoa adierazten du. Udalerrietako elite kulturala osatzen zuten aberats, agintari eta elizgizonek gaztelaniaz edo beste atzerriko hizkuntzetan bakarrik ikasteak eta beren irakurraldi eta idazlanetan ere hizkuntza horiek besterik ez erabiltzeak bere euskararen mailaren jaitsiera nabarmen bat eragin zuten. Egoera hau benetan larria gertatzen zen herriari dotrinaren eta moralaren edukiak irakatsi behar zituzten apaizen artean. Batetik, atzera eraginezko ondorio bat ari zen gertatzen : apaizek euskara gero eta gutxiago erabiltzeak hizkuntzaren pobretzea zekarren eta alderantziz. Bestetik, gero eta maizago apaizek gaztelaniaz predikatzen zuten entzuleek ulertzen zuten edo ez axola gabe. Bi gertakariok gogor salatu zituen aita Larramendik euskaraz besterik ez zekien gehiengoaren dotrina eta moral katolikoaren ezagutzak zalantzan jartzen zituztelako ${ }^{18}$.

16 - IEA, Ollo, c.1604- n 3

17 - IEA, Ollo, c. $1604-\mathrm{n}^{\circ} 3$

18 - “... De esta excusa nace el abuso de que nos envíen a la scomunidades de Guipúzcoa predica dores castella nos que predican al pueblo en castella no, con gran satisfacción de que son entendidos, siendo certísimo que, de mil oyentes, no habrá cincuenta que los entiendan pa ra que saquen algún fruto; y todos los demás, o están dormidos, o están oyendo como si los oyeran predicar en griego (...)

Lo que es más intolerable es, que suben al púlpito predicadores vascongados y predican en castella no, no a treviéndose a hacerlo en vascuence. No quieren trabajar ni a plica rse a saber bien su lengua, ni a leer y escribir en ella. Tienen sermones en castellano que encuentran trabajados y de molde en romance. Pa ra traducirlos se necesita de inteligencia y saber bien una y otra lengua, a sí en la extensión y multitud de voces y sentido de ellas, como principalmente en la colocación y gra mática de una y otra lengua. No saben palabra de eso, y no quieren 


\section{Elizgizonek bultzatutako erreakzioa}

Guztiz euskaldunak ziren lurraldeetan bizi ziren elizgizonen artean euskararen ezagutza ezinbestekoa ez izate honek berebiziko ondorioak ekarri zizkion euskal kulturari. Elizgizonek euskara behar bezala ez lantzeak herri xumearen artean dotrina eta moral katolikoaren ezagutza zuzena eta zabalkundea arriskuan egoteraino iritsi zen XVIII. mendean. Ondorioz mende honen erdi aldera elizgizonek hizkuntza erreakzio moduko bat hasi zuten, elkarrekin oso loturik dauden bi gertakariri hasiera emanez. Batetik, sermoietan eta predikuetan erabiltzen zuten euskara lantzeari ekin zioten herriarentzako ulergarriak eta ulerterraxak gerta zitezen. Bestetik, "Larramendiren eskola" bezala ezagutzen den euskal idazle eskola entsutetsua eratu zen.

Larramendik gogor kritikatu zituen, goraxeago aipatu denez, euskaraz predikatu nahi ez zuten edo alferkeriz euskara landugabe eta zabar bat erabiltzen zuten sermolariak, horrela arituz oraindik hutsik euskaldun izaten jarraitzen zuen herri xumearen fede eta dotrina ezagutzak gero eta urriagoak izan zitezen ahalbidetzen zelako. Eskola honetako lehen euskal liburua, aita Sebastian Mendibururen Jesusen Bihotzaren Devocioa, 1747an irten zen argitara. Idazlan honen hitzaurrea Larramendik idatzi zuen, bertan euskara landu edo erabili nahi ez zuten apaizen aurka gogor egiten zuelarik: "Siñis na za zu, ereille ga istoeta n da go a za ro charra, eta gero uzta soilla ta utsa. Alabañan guchik daki bere jaieterriko euskeraren erdia, eta alperrak diraden bezala, eztute ikasi nai geiago, ta eztie nai beren buruai atsekaberik eman. Baña onetatik zer gertatzen da ? Dakiten piska arekin, hitz molcho, eskumen baten diña eztan arekin, nola eziñ adierazi dituzten beren esakariak, badarasate pulpituan hitzera naasi bat, beiñ euskera, beiñ erdera, beiñ latiñera, guzia leudatua, zikindua, beraustua : zeñean dirudien igo direla gaiñ artara entzule guzien burla egitera (...). Are gogaikarriena da charleri oiek ikustea ta a ditzea nola dauden isekaz ta musinka euzkeraz ederki dakienen sola sari, beiñ Nafarroako mintzoa dela, gero Bizkaiko berba dongea, ba tean a usaz ere Goierriko hizketa dezula, bestean noaskiro Beterrikoa; achurlarien ta nekazarien hitzera da la hura, ba serritarra dirudizula , ta milla onelako astakeria..."19.

XVIII. mendearen erdi aldera fedearen edukiak behar bezala zabaltzeko euskara erabili eta lantzearen aldeko erreakzio eliztar honen abiarazleak, Larramendi berak aitortzen zuenez, Zarauzko frantziskotarren komentuko seminarioko kideak izan ziren gehien bat, herriz herri euskaraz predikatuz zebiltzan misioak antolatuz ${ }^{20}$. Seminario hori 1746an sortuz batera euskaraz predikatu eta aitortzak egiteko gai

a plicarse ni trabajar para saberlo, con poca vergüenza de su ministerio; y rompen con el castellano, que acaso en cien cosas que predican no lo entienden. ¿No es esto hacer burla del púlpito, del a uditorio y de la pa labra de Dios? Yaun ha llegado la infamia a valerse de estos predicadores para que en muchos pueblos, comunidades de monjas y cofradías, se tenga por cosa de menos valer el que se predique en vascuence, como que el vascuence es sola mente lengua para aldea nos, caseros y gente pobre (...)

Que esa máxima tenga a cogida y aceptación entre jóvenes que vienen de colegios, de semina rios, muy imbuídos de bellas letras, y del la tín, romance o francés en que las han estudiado, y que la practiquen en conversaciones sobre esas materias que no son comunes ni populares, pase, pues que hasta a hora no se han escrito en vascuence. Pero que así estos jóvenes como otros ancianos, sean clérigos, religiosos y seglares vascongados, entablen conversación sobre materias usuales y comunes y se desdeñen de hablar en ellas en la lengua materna del país, como que esto es cosa de menos valer, es irracionalidad y locura. Pues iqué discreción será y qué racionalidad valerse de esa máxima falsísima e indigna, en las iglesias, en los púlpitos, en que se deben predicar materias e instrucciones santas, inteligibles y perceptibles, no sólo de los doctos, sino de los ignorantes y vulgares ?..." (LARRAMENDI, M. : Corogra fía o descripción..., op.cit., 286-288 or.).

19 - LAFITTE, P. : Eskualdunen Loretegia. XVI garren mendetik huna teko liburueta rik bildua. Baiona : Lasserre Liburutegia, 1931, 66-67 or. 
ziren elizgizonak bildu zituen bere baitan eta euskal sermoiak, misioak eta erlijio liburuak idatzi eta zabaltzeari gogor ekin zioten ${ }^{21}$. Apaizgaitegi honetako fraideen lana dela eta aita Larramendi bezalako elizgizonena dela, ukatu ezinekoa da euskara lantzearen aldeko eliz erreakzio hau zabalduz joan zela XVIII. mendearen bigarren erdian zehar. Horren lekuko Iruñeako Artzapezpikutegiko agiritegian gordetzen diren Gipuzkoako Artzapez-barruti Txikiko agiri judizialak beste behin ere oso adierazgarriak dira.

Euskaraz emandako elizkizunetara askoz ere eliztar gehiago gerturatzen zirela eta horrela fedearen edukiak hobeago zabaltzen zirela ikusirik, 1777an Hondarribiako parrokiako bikarioa zen on Roque Jazinto de Salazarrek Iruñeako Artzapezpikutegian aurrerantzean Hondarribian bakarrik euskaraz predika zedila eskatu zuen. Bere eskakizunean zioen "...procurando el maior bien espiritual de sus feligreses y que los sermones y platicas produzcan el frutto a que se dirigen a medita do sobre el modo que esttos serian mas utiles: y considera que no puede haber medio mas proporcionado que el que se prediquen en basquence por ser estte el ydioma propio del Pa is que todos entienden y al contra rio el ca stella no : y por eso se hacen en la misma lengua los examenes de docttrina, confesiones, protestacion de la fe en los enfermos y en fin qualquiera punto de considerazion aun en la sala consistorial se confiere en vascuence, y por eso es sin comparacion maior el concurso a los sermones que se predican en ese idioma quales son los de adbiento de partte del vicario desde el año de1774; y la misma ciudad dispuso que en el año de 1761 se predicase en el propio lenguaje el Sermon de Pasion, y desde entonces se continua con ese metodo, y quando desea se aga saber al publico alguna cosa de ymportancia se egecutta // (1. al. or.) assi el Regimiento : y en el año ulttimo de 76 habiendo encargado mi partte al predicador hordinario en el sermon de tabla esplicase por punto de docttrina la Bula de la Cruzada, por haberlo egecuttado en romance y con alguna concision, dispuso mi partte que la misma tarde su thenor la explicase en lenguaje bascongado y se logro el frutto de haber pedido de nuebo tanttas bulas que habiendo agotado las que habia en dicha ciudad se pidieron algunas a la de San Sevastian : y lo que a todo echa el sello es el que Su Señoria Mustrisima en su santa visitta de el a ño de 1771, predico en bascuence..."22.

Eskakizun hau kontuan hartua izan zen artzapezpikutegiko agintarien artean, izan ere elizbarrutiko Bikario orokorrak zera agindu baitzuen : “...vista esta petizion se manda que todos los sermones y platicas doctrinales que estan al cargo del vicario de la parroquial de la ciudad de Fuenterravia y su theniente por sus respectibos ministerios se prediguen en el idioma bascongado por ser este el propio y na tibo de a quel Pa is yel que mas a comoda a la instruccion e inteligencia de susfeligreses, yque lo mismo se egecute por los demas predicadores en los sermones morales, cuia limosna se costease de los efectos y rentas de la mencionada yglesia." ${ }^{\prime 23}$. Dena dela Hondarribiako bikarioa ez zen gustora geratu lorpen honekin, izan ere euskaraz

20 - "...Ya es tiempo de hacer la excepción que tengo ofrecida. No se puede dudar que, de pocos a ños a esta parte, se predica en vascuence menos mal que antes, y que hay predicadores que en sermones morales predican absolutamente bien y con limpieza, y con gusto y fruto de los oyentes. Así por lo común los misioneros en sus sermones, y con especialidad los franciscanos misioneros de Zara uz que, a su mucha virtud yobservancia, yal celo de las almas, han a nadido el cuidado y trabajo de predicar un vascuence claro, inteligible, limpio y bien ordenado, según el ca rácter y sintaxis de la lengua, y desmientesn con su práctica las quejas mal fundadas de los va sconga dos holga za nes..." (LARRAMENDI, M. : Corografía o descripción..., op.cit., 286-288 or.).

21- ITURRIA, K. : "Euskal literatura Zarautzen", Za ra utz-ko go rabeherak historian zehar. Za ra utzi buruzko ikerketak-en. Zarautz : Zarauzko udala, 1987, III. alea, 19-60 or.

22 - IEA, Ollo c.2309 - $\mathrm{n}^{\circ} 13$.

23 - IEA, Ollo c.2309- $\mathrm{n}^{\circ} 13$. 
bakarrik predikatzeko aginduak ez baitzituen hartara behartzen udalak kontratatutako kanpoko sermolariak. Ondorioz beste eskakizun bat helarazi zuen Iruñeara, udalak hiritik kanpo kontratatutako sermolariek ere bakarrik euskaraz predikatzera behartuak izan zitezela eskatuz. Elizbarrutiko Bikario orokorrak ordea ez zuen eskakizun berri hau onartu bere epaian eta ondorioz Hondarribiako bikarioak Calagorriko Auzitegi Metropolitarraren aurrean apelatu zuen ; dena dela auzitegi honen epaiaren berririk ez dugu aurkitu.

Egia da erreakzio hau ez zutela elizgizon guztiek berdin onartu. Larramendi berak aitortzen duenez euskaraz sermoiak egiteak edo idazteak zekarren lana egin nahi ezak elizgizon asko erreakzio honetatik at geratzera bultzatu zituen, batez ere jesuiten artean. Larramendik gogor kritikatu zituen bere ordenakideak, beste eligizonek ez bezala euskara lantzearen inguruan zuten jarrera ezkor honengatik, esanaz: "...a lo menos están viendo que después acá se predica la palabra de Dios con fruto, limpieza y decencia, y es lo que no habían antes. Ven que ya se habla, se escribe, se imprime en vascuence, y que de esto se me dan a mílas gracias por los instruídos vascongados, franceses y no franceses; y sólo entre jesuitas no encuentro uno de estos a gradecidos. Yes chiste, que predican mejor con exceso los Misioneros de Za ra uz y fra iles de otras Ordenes y clérigos, que estos murmura dores jesuitas, que por lo común son haraganes, no saben escribir ni aun leer su vascuence..."24.

Larramendiren azken aipamen honetan ederki ikus daiteke elizgizonen erreakzio honek berebiziko garrantzia izan zuela euskal literaturaren historian, izan ere Euskal Herriko hegoaldeko lehen idazle eskolaren sorrera eragin baitzuen. Lehenago kristau-ikasbideren bat edo beste euskaraz argitaratua izan bazen ere ez zen inoiz idazle eskolarik sortu Larramendiren bultzakadaren aurretik. Idazle eskola honen helburu nagusietako bat fedearen edukien zabalpena sustatzea izanik ere -idazlan gehienek fede eta erlijio kutsua dute-, hizkuntzari eta euskal literaturari dagokionez aurrepausu oso garrantzitsua izan zen. Are gehiago XVIII. mendeko euskaldun ikasiek ere horrela ikusi zuten, aurreko Larramendiren aipamenean irakur daitekeen bezala. Aipamen horretan dio euskaldun ikasi askok eskerrona azaldu ziotela bere bultzatzaile lanarengatik, eta euskaldun ikasi horietako gehienak "frantsesak", hau da, Ipar Euskal Herriko biztanleak zirela. Kontuan izan behar da Lapurdin oraindik bizirik jarraitzen zuela XVII. mendean sortu zen "Sarako eskola" deituriko literatura mugimendua ${ }^{25}$. Mugimendu hau ere Trentoko Kontzilioak bultzarazitako fede eta doktrinaren ezagupenerako herri hizkuntzen erabileraren testuinguruan sortu bazen ere, urteak aurrera joan hala gai mundutar orotako idazlanak eman ziren argitara. Eskola honek euskaraz idazteari eman zion bultzakada benetan garrantzitsua izan zen, Lapurdiko biztanle ikasi zenbait beren eguneroko idatzizko harremanetarako euskara erabiltzeraino iritsi baitzen ${ }^{26}$.

24 - TELLECHEA IDIGORAS, J. : Obras del Padre Larramendi : Autobiografía y otros escritos. Donostia : Sociedad Guipuzcoana de Ediciones y Publicaciones, 1973, 29 or.

25 - Beraz, Larramendiren azken aipamen honetan ikus daitekeenez Iparraldeko literatura mugimenduaren eta XVIII. mendearen erdi aldera Gipuzkoan sortu zenaren artean harreman zuzenak izan ziren. Harreman hauen lekuko, Sarako Joannes D'Etcheberri dotoreak idatzi eta 1712an Lapurdiko Biltzarrean aurkeztu zuen euskarazko latin gramatika Zarauzko Misiolarien Seminarioko agiritegian dagoela gorderik. Dirudienez, 1803an iritsi zen bertara, Etcheberriren ondorengoren batek edo aita Pedro de Astarloari eman ondoren -izan ere bere bizitzako azken urteetan Hondarribian eta Azkoitian bizi izan baitzen eta bere seme bat Mutrikura eskondu zen, oinordekotza zabala izanaz-. Ikusi : ITURRIA, K. : “Euskal literatura Zarautzen..., op.cit., 39-43 or. ZUBIAUR BILBAO, J.R. : "El euskara en Amasa-Villabona. El escritor Juan Antonio de Ubillos Galatas. Su obra en euskara", ORELLA UNZUE, J.L. (Dir.) : Historia de Amasa y Villabona. Amasa-Villabona: Amasa-Billabonako Udala, 2003, 215-241 or. 26 - ALBERDI LONBIDE, X. - RILOVA JERICÓ, C. : Iraganaren a hotsak..., op.cit. 
Larramendik bezala, Cardaberazek ere 1761ean argitaratu zuen euskal gramatikan beren euskara lantzera adoretzen zituen elizgizonak. Baina elizgizonek bultzatutako erreakzio honetan Kardaberazek beste aurrerapausu bat eman zuen. Aipatutako idazlan honetan herrietako agintariak eta lehen hezkuntzako maisuak euskaraz irakatsi beharraz ohartzen zituen. Kardaberazek garbi zion herri xumearen, pobreen artean fedearen eta dotrinaren edukiak zabaltzea beharrezkoa zela, beren gizarte eta ekonomia egoera kristauki onar zezaten eta agintarien eta aberatsen aurka ezer egin ez zezaten ${ }^{27}$. Kontuan izan behar da XVIII. mendean -batez ere bigarren zatianeliteko kideen eta herri xumearen arteko desberdintasuna bere maila gorenera iristen ari zela eta, ondorioz, pobreen kopurua handitu eta Matxinadak eta antzerako gizarte gatazkak sortzeko arriskua ikaragarri handia zela -are gehiago 1789 az geroztik Frantziako Iraultza hasi zenetik-.

Zaldibian eta Ataunen frogatu ahal izan ditugun bezalako euskarazko irakaskuntzaren adibideak bazirela aipatzen ditu Kardaberazek -nahiz eta herrien izenak aipatu $\mathrm{ez}^{28}$-, eta Euskal Herri osora zabaldu behar zutela tinko esaten zuen eskoletan euskara ikasleen artean erabiltzearen aurkako neurriak ezabatu egin behar zirela: "...Bizcaian, ba ita emen gure artean ere Sacerdote ja un a sco icusi ditut Escoletan obra on ori celo, ta arreta a ndiaz eguiten : obra obeagoric Errientzat ecin, a lafede umeac ondo aztcea baño, eguindezaquee. Argatic Ma isu eta Guraso umeai eractsi bear dienac, ori ondo eguiteco Erreglac bearrago dituzte. Seme, ta alabac chiquitatic Escolan Erdaraz, ta Euscaraz, edo guztitara oitu bear dira, ta arrazoi gabeco lotsa beltz ga isto a pisatu, ta quentcera. Bestela cer lotsa ga isto itsusiagoric, Euscaldun galtzadun, edo guizon eguin bat, lau errengloi Eusqueraz ecin iracurriric, ez atcera, ta ez aurrera, ta icustea baño ?(...)

Emen Guraso, ta Maisuac falta andibat erremediatu bear dute, ta gure Eusquerari orañdaño baño mesede gueiago eguiñ. Gendeen artean beste Lenguageric Eusquera baño dicha gabeagoric ezta icusi, ta, gure jatorrizco, edo ja iotzaco Izquera ezbaliz bezala, ta Euscaraz itzeguitea, pecaturic aundiena baliz bezala, guiza artetic quendu, ta lurpean ondatu nai dute, ta Escoletan sortija, edo siñaleaquin, azote ta castiguaquin eragotci nai dute. Cer eraqueria itsuagoric au baño ? Euscaldun prestuac, ez arren orrelaco ofensaric zuen lenengo, ta beti bear dezuten Eusquerari eguin. Zuen juicioa nonda ? Euscalerrietan nola gauza onic izangoda ?...'29.

27 - “...Dotrinaren puntu chit bearrac dira, umeac Jaincoaren bildursantuan acitceco legueac: Guraso, ta familia buruac oriec ondo zucentceco, eta umeen Gurasoaquico amorio, obediencia, ta errespetoaren obligacioac: Dotrina icasi, ta eracustea, confesa tcera bialtcea, lagun onaquin ibilli, ta goiz echeratcea, echeco paquea, ta elcar ondo artu, ta icustea : bere, ta echecoen estura, gaitz, edo nequeac pacienciaz, ta Ja incoaren icenea n ondo eramatea : nola orietan Ja unaren erregalo, ta gora ñtci gozoetan bezala, a ren boronda tea eguitea, Jesus onaren ceruraco bide erreal segurua dan : nola gure dicha gucia, gure borondate ucatu, a utsi, ta ez ori, ezpada Jaincoarena eguitean dagoen : bacoitzac bere estadu, ta bicimoduco gurutce, ta carga a morez egunoro artu, ta Cristori gogotic jarraicean dagoen (...)

Orrega tic pobreac zuen artean beti, Cristoc dionez izangodituzue Erribestecoa i bere liberta de esquecoa quenduco etzaie. Ba ña orien artean cembat dabiltza, ta norc daqui nola, ta cer leguetan ? Ez dotrinaric daquiten, ez ezconduac, a la bestelacoac diran, non, da noiz confesa tcendiran: Errico ta Eleizaco buruen quezca, ta oriequin ecin buruatua : ceren batetic bestera iguesca dabiltzan. Ta cembat Sacramentu, ta confesio gabe, gaizqui bide orietan illic topatcen dira ?.." (CARDABERAZ, A : Eusqueraren berri onac..., op.cit., 53-56 or.).

28 - "...Bedeica nic daquidan Maestra estima ga rri errespeto andico bat, bere gracia onarequin, ta castigu gabe ume inocente, sei urtecoai ere, Eusqueraz, Erderaz, ta La tinez berdin, chit trebetasun andiaz, ta ederqui lotsa ric gabe iracurten eracasten diena. Ojala ori bera Maisu guciac eguiten balute: mutil mutu, lotu, motel guchiago Errietan izango litzaque. Baña utseguitean, oiei soseguz, ta gracia onean, nola ondo iracurri, edo esan bear duten, a dieraci bear zaie, eta ez bildur, ta ica raquin. Oitu bear dira, ez emengo Izqueran bacarric, ezpa da edoceñ Dialectotan, eta Francia edo Nafarroaco, edo Bizcaico Libruetan ondo, ta trebe iracurtera..." (Ibidem, 19 or.). 29 - Ibidem, 16-17 or. 
Haurrak euskaraz ere hezitzeari berebiziko garrantzia ematen zio Kardaberazek, izan ere lehen eskola horietatik irtengo baitziren etorkizuneko elizgizonak eta agintariak. Beraz, etorkizunean herri xumearengan Kristorenganako fedea, dotrina katolikoaren edukiaren ezagutza eta agintariekiko begirunea eta menpekotasuna sustapena ziurtatzeko, eskolara joan ahal zuten eliteko kideen haurren euskara maila ere landu beharrekoa zen eskoletan. Aipatzen ari garen idazlan honetan behinola erregearen gudarosteko ofizial arabar batek zuzendu zion galdera oso esanguratsu hau biltzen du : “...Aita, nola Euscalerrietan, umeen aciera ona, ta bear dan Dotrinaric izangoda, baldin Eusquera ondatceco aleguiñ guciac eguiten badira, ta gure mutilcho, edo a urrai bildur, ta azoteaquin, Eusqueraz itzeguitea eragozten bazaie ? Oiec berac güero edo Eleizaguizon edo Echajaunac izan bear dute. Eta Guraso, edo curac diranean, nola ongui premia dan bezala beren Eche, edo Ergoienetan (Erri chiquiai onela Araban deitcendiete) Dotrina eracatsi, ta confesatucodute? Nola beren familietaco artu emanac, ta beste bear diran gauzac ondo a ditu, ta zucenduco dituzte ?..."30.

Agian etorkizunean fedearen eta dotrinaren ezagutza eta agintariekiko menpekotasuna ziurtatzea, izan liteke Goierriko zenbait herritan XVIII. mendeko bigarren erdialdean euskaraz irakastearen arrazoia. Etorkizunean ere herritar xumeei ulergarriro ideia horiek helaraziko zizkien elizgizonak eta agintariak beharbeharrezkoak izango ziren gizarteko goi mailako sendiek beren botere ekonomikoa eta soziala gal ez zezaten. Beraz, euskararen ezagutza maila eskoletara joaten ziren aberatsen haurren artean ezinbestez landu beharreko gaia zen, zetozen urteetan ere herri xumearen lanaren kontura aberats izaten jarrai zezaten eta elizako, udaletako eta Probintziako aginte karguen berenganatzea herritar xumeen aurkaritzak arriskuan jar ez zezan.

\section{Ondorioak : zergatik irakasten zen euskaraz Goierriko zenbait herritan ?}

Orain arte esandakoarekin lan honek dakartzan ondorioak nahiko jakinak izango dira irakurlearentzat. Egia da arestian aipatutako beharra, hau da, etorkizunean herri xumearengan kristau fedearen eta dotrina katolikoaren ezagutza sustatzeko eta agintariekiko atxekipena lortzeko haurrak euskaraz hezi beharra, Gipuzkoako herri guztietan berdina izango zela. Beraz, zein zen bada arrazoia Goierriko zenbait herritan euskaraz irakasteko beste askotan hizkuntza honen erabilera bera galarazten zuten bitartean ? Goierriko aipatutako herri horiek zeharo nekazal girokoak ziren eta beraz pentsa dezakegu biztanlego ia guztiak ez zuela euskara besterik jakingo. Beraz, euskara hutseko egoera horretan biziko ziren etorkizuneko biztanleek ere fedeak eta dotrinak zekarzkianak eta apaizek pulpitutik esan eta zabaldu nahi zituzten ideiak inolako arazorik gabe uler zitzaten, ezinbestekotzat ikusiko zuten eliteko kideen haurrei euskaraz irakastea -gaztelaniarekin batera-. Kontuan izan behar da, Gipuzkoako beste zenbait herritan elebitasuna asko hedatu zela XVIII. mende erdirako, Hondarribiako inguruetan gertatzen zen bezala lehenago ikusi dugunez. Ondorioz, udalerri horietako agintariek ez zituzten Kardaberaz bezalako elizgizonen hitzak eta oharrak aintzakotzat hartuko bere eskoletan ere euskaraz irakatsi zedin. Agian, gainontzeko udalerri horietan ez zuten hainbesterainoko arriskurik ikusiko herri xumearen fede eta doktrina ezagutzen mantentzerako ${ }^{31}$.

30 - Ibidem, $17-18$ or.

31 - Historialarien artean azken urteetan zenbait eztabaida izan dira Aro Berriko agintariek erlijio federik ba ote zutenaren inguruan. Ikerlari batzuen aburutan, agintariek ez zuten inolako federik edo sinesmenik eta erlijioa herri xumea menperatzeko erabiltzen zuten zinismo hutsez. Ikusi : HARRIS, M. : Vacas, cerdos, guerras y brujas. Los enigmas de la cultura. Madrid : Alianza Editorial, 1992. 
Askotan esan ohi da Borboitarrak Espainiako Koroara iritsi zirenetik kultura uniformizazio prozesu bati eman ziotela hasiera, euskararen erabileraren aurka arituz. Ideia hau dokumentazioaren argitan ez da inola ere onargarria. Errege agintariek ez zuten inolako interesik azaldu euskararekiko, ez alde ez aurka. Bertako, hau da, Euskal Herriko herrialde desberdinetako elizgizon eta agintariak izan ziren euskararen erabileraren eta lantzearen aldeko edo aurkako neurriak bultzatu zituztenak, tokian tokiko eta garai desberdinetako interesen arabera. Hau da, helburu berdinetara iristeko -fedearen eta dotrinaren ezagutza, eta agintariekiko menpekotasuna- garai eta leku desberdinetan zirkunstantzien eta behar linguistikoen arabera, euskararen alde edo aurka aritu ziren. Honela uler daitezke zenbait herrien arteko ezberdintasunak euskara irakasteko orduan. Esan behar da, halaber, euskararekiko begirunearen jatorria ez dela hizkuntzarekiko maitasun hutsa, praktikotasuna baizik, hau da, fedea eta dotrinaren garbitasuna bermatzea, eta norberari munduan bizitzea tokatu zitzaion egoera itsuki onartzea.

Azkenik, berriz esan XVIII. mendean Gipuzkoan elizgizonek hasitako hizkuntza erreakzio honek berebiziko eraginak izan zituela euskal kulturarengan. Mende bat lehenago Lapurdin gertatu zen bezala, fedearen eta dotrinaren edukiak behar bezala herri xumearen artean zabaltzeko, euskara maila lantzera eta euskaraz idatzitako erlijio liburuak idaztera bultzatu zituen elizgizonak. Hau izan zen Larramendiren eskola deituriko literatur mugimenduaren jatorria. Aldi berean, etorkizunean ere helburu hauek bete ahal izateko, Hego Euskal Herriko historian zehar lehendabiziko aldiz euskarazko irakaskuntzaren hastapenak sortu ziren. Guk lan honetan aurkeztutako agiriok benetan euskaraz irakastera iritsi zirela frogatzen dute, Goierriko herri batzuetan bada ere. •

\section{Eranskina}

Lehenengo agiria : Miguel de Gurrutxagak Zaldibiako Udalarekin sinatutako lehen hezkuntzako irakasle-kontratua (1757).

Zaldivia 15 de marzo de 1757 / De tra sla do / Escritura de a siento y conduzion de maestro de escuela de niños d'esta villa / En la villa de Zaldiuia a quince de marzo de mil / setecientos y cinquenta y siete ante mi el escriuano publico / y testigos infraescritos parecieron presentes de la vna parte los/señores Juan Antonio de Irastorza Juan Ignacio de / Echaue Juan Ignacio de Jáuregui de Zela a y Ignacio / de Jauregui de Olano alcalde regidores y sindico procurador general / de esta dicha villa en su nombre y representación. Y de la otra Francisco / Miguel de Gurruchaga natural de la población de Urres / tilla residente en esta dicha villa. Ydixeron que en a iuta / miento general de ella se acordo que el dicho Francisco Miguel de / Gurruchaga de profesión maestro de escuela de niños seruie / se a esta dicha villa y a los niños y niñas de sus vecinos y mora /dores enseñándoles a ler (sic) escriuir y contar y los rudi / mentos de la Dotrina Cristiana y se escriturase su con / ducion y en este supuesto esta seruiendo a esta villa / por tal maestro de escuela desde primero de henero vltimo / y para que tenga efecto lo a si acordado en dicho ayuntamiento /los dichos señores a lca lde regidores y sindico en representa ción / de esta dicha villa otorgan por esta carta que le admiten / por tal maestro de escuela de niños y niñas de sus vecinos y // (92. aldea or.) moradores y hacen asiento para tiempo y espacio de / nueve años que comenzaron a correr el citado dia pri / mero de henero vltimo y por salario ordinario a darle / y pagarle en cada vn año veinte y on ducados de vellon / de los efectos y rentas de esta dicha villa siendo el primer / plazo en primero de henero del año proximo venidero / de mil setecientos y cinquenta y ocho y adelante subce / siuamente al mismo plazo de los años que se siguieren / durante la dicha conducion. Yademas del dicho sala rio / le daran para su hauitacion durante dicho tiempo la cozina / y a posento que esta casa concegil tiene 
hacia la de Albi / su y otro aposentico que se halla a la entrada de la puer / ta de dicha cozina y la cambara (sic) que esta cerrada en / el suelo alto de esta dicha casa concegil hacia la parte / que cae al molino de Campain. Yademas la sala / de la dicha escuela que se halla en el suelo de hacia la / dicha casa de Albisu pegante a la carcel pa ra que en ella / a sistan los niños y niñas de dichos vecinos y moradores / en las horas a costumbradas le daran a su disposicion / durante la dicha conducion al dicho Francisco Miguel de Gurruchaga siendo para este el trigo y maiz que / los dezmeros de esta villa a costumbran contri / buir que son vna fanega de trigo y otra de maiz / en cada año por (LERRO ARTEAN : la libertad de) recoxer a dicha sa la los diezmos // (92. iruntzia or.) de trigo y maiz en cada año. Esto es si dichos dezme / ros recoxieren a dicha sa la sus diezmos y la tercia par / te de la huerta de esta dicha casa concegil le da ran ta mbi / en pa ra que se vtilize de ella para su hortaliza durante / el tiempo de la dicha conducion y fuera de todo lo referido cada / ono de los niños y niñas que a sistieren a dicha su escuela le / haian de contribuir y pagar mensualmente hasta ponerse / a ercriuir a real de vellon. Los escribientes a dos reales / de vellon y los contadores a tres reales de vellon en cada mes. / El dicho Francisco Miguel de Gurruchaga otorga que acepta / esta escritura en todo y por todo y se da por conducido en el em / pleo y exercicio de tal maestro escuela para los expresados nueve / a ños y durante ellos por el sala rio y emolumentos suso / referidos se obliga a la asistencia que requiere el empleo de / tal maestro de escuela y a enseñar a los niños y niñas que asis / tieren a su escuela con toda la diligencia posible a ler es / criuir y contar y a instruirlos en los rudimentos de / la dotrina cristiana asi en la lengoa castella na co / mo en la de bascuenze cumpliendo exactamente con su obli / gación. Y todos los otorgantes por lo que a cada vno toca /guardar y cumplir lo contenido en esta escritura obliga ron / a sa uer los dichos señores capitula res los propios y rentas / de esta dicha villa. Yel dicho Francisco Miguel su persona y vie / nes muebles y raices hauidos y por hauer.

(Gipuzkoako Agiritegi Orokorra, PT IPT 1916, 92. al. or.- 93. ir. or.)

Bigarren agiria : On Joaquin de Asurmendik Ataungo Uda la rekin sinatutako lehen hezkuntzarako irakasle-kontratua (1791).

Ata un 18 de setiembre de 1791 / Asiento del maestro de primeras letrascon las / condiciones impuestas por el mejor desempeño de sus / cargas entre esta villa y don Joaquin de / Asurmendi conducido por tal maestro / En la sa la de ayunta miento de esta noble y leal villa de Ataun / a diez y ocho de setiembre de mil setecientos noventa y / ono ante mi el escribano publico y testigos infraescritos parecieron / presentes de la ona parte los señores don Joaquin Tomas de Be / guiriztain Juan Antonio de Apaletegui de Ocaraizti Felipe / Antonio de Zurutuza Pedro Antonio de Aierdi y don Juan / Antonio de Mujica alcalde regidores sindico procurador general / vecino concejante de esta referida villa y comisionados para / lo infraescrito del ayuntamiento general de vecinos de ella de que yo el escriba no / doy fe. Y de la otra don Jose Joaquin de Auzmendi maestro de primeras / letras y organista de la parroquial de la misma villa. /Ydigeron que habiéndose reunido los empleos de maestro / de primeras letras de esta villa y de orga nista de su parroquial / por el orden de quince de setiembre de mil setecientos ochenta $y$ /cinco se procedio a otorgar escritura de conducion a favor de / dicho Asurmendi en diez y nueve de febrero del siguiente / año de ochenta y seis y habiendo obtenido cien ducados / anuales de aumento de sala rio sobre igual cantidad con / que estaba dotado del caudal de propios y los mil cien reales que / percibe de la fabrica de dicha iglesia por Real Orden de seis de // (178. or. aldea) junio de este año ha pedido con este motivo se le otorgue / nueba escritura y hallándose la villa sa tisfecha de su buen proceder / y en a tención a sus meritos ha acordado que a si se egecute / vajo la scondiciones convenientes y mediante su comision / establecen las siguientes: / Primeramente que en todo y por todo se 
hayan de obser / bar las referidas dos Reales Ordenes y las demas que tratan del magisterio de primeras letras cumpliendo / con exactitud con lo que en ellas se ordena y manda. / Que a sista el maestro a la escuela con los niños todo el año / a la socho de la mañana y los saque a las once y por la / tarde entrando a la una salgan a las qua tro. / Que exceptuando los dias de precepto y los de la conversión de / San Pablo San Gregorio San Silberio San Pelayo Remedios an / tes del carna val ceniza s juebes viernes y sabado santo y / San Nicola s a sista el maestro con sus niños a la escuela / sin que le valga pretexto alguno. / Que las visperas del angel de guarda a sencion del señor / Pentecostes trinidad corpus San Juan Bautista San Martín / y los sabados de todo el año a sistan los niños a la vna / de la tarde a la escuela y el maestro les pregunte la / doctrina hasta las dos y media y hasta el instante que / entren a vispera s a las que deberan a sistir los dias solemnes / que por principio van señalados. / Que por las mañanas traigan los niños procesos cartas / o qualquiera manuscrito asi para deletrear como para leer y / por la tarde libros o catones. Que el maestro ponga el ma / ior cuidado en enseñar a deletrear y no ponga a ninguno / a leer sin que primero este mui corriente en deletrear // (178. iruntzia or.) y sin que este mui corriente en leer no ponga a escribir / y los escribientes tomen del maestro el papel y tinta pa / gando lo que es justo. / Que sea de la obligación del maestro enseñarles la tabla de / contar a los escribientes quando estos se pongan en letra pequeña. / Que después que el ma estro toma la slecciones a los niños I pasen estos los principiantes a vn corrillo con vno que sea / adela ntado para que este les enseñe a persignar padre / nuestro ave maria credo y salbe en otro corro se ponga / otro a enseñar los mandamientos de la ley de Dios / articulos de la fe mandamientos de la iglesia obras / de misericordia y santos sacra mentos y después que a pren / dan lo dicho arriba pa sen a otro corrillo en donde se enseñe / la dotrina y todas estas diligencias se hagan por la mañana / en vascuence y por la tarde en castellano y al canten las / oraciones como se a costumbraba en tiempo del difunto / Arsumendia a plicándolos a canta r el santo Rosa rio y / letania de Buestra Señora y santos previniendo que los / viernes por la tarde debera instruirles en la letania de los / santos y los sabados por las tardes en la de Nuestra Señora. I Que por si o por medio de otro procure ponerlos en orden / en la procesión y ponga dos acusadores para que estos cuiden / a si fuera como dentro de la iglesia y den parte al maestro / de sus culpas o defectos especialmente que se aparten de los / concursos de mayores que siempre que se encuentren con / ellos se quiten los sombreros o monteras saludándoles / con respeto y veneración que no anden a pelota ni otro / juego en el cla ustro ni en el cubierto de la casa concegil // (179. aldea or.) ni tampoco anden a las orillas del rio y caso de inobe / diencia o exceso los castigue el maestro sin respeto a sus / padres según la merecieren. / Que el maestro tenga obligación de tener el organo todos / los dias del año en misa mayor en la que canten qua tro / o seis niños que tengan mejores voces a elección del maestro / y todos los demas la oigan con la debida compostura bolbien / do con el maestro a la escuela. Que los dias que no haya organo tenga obligación de cantar la misa a unque sea de / Réquiem. Que siempre que le comprenda la obliga ción / de a sistir a la escuela no a sista a cantar nocturnos. / Que en los bautizos no pueda tañer el organo a ninguno / sin ser lla mado y a un quando lo sea solo pueda tañir / no estando ocupado en su ministerio. / Que tenga obligación de tañer las misas de Nuestra Señora / salves y demas funciones que se hacen entre año. / Que quando tenga precision de ausentarse aunque sea / por on dia pida licencia a los señores ca pitula res y estos / se la concedan o nieguen según los motivos que expusiere / y a un en ca so de que se le conceda sea poniendo substituto de sa tisfacción. / Que por cada dia que deje de a sistir a la escuela sin mo / tivo justo se le rebajen de su sa la rio seis rea les de vellon. Que deba los sabados señalar los que se han de vestir de aco / litos y cuidar de misa pa ra las mayores y recibir las ofrendas y llebar la paz como es de costumbre. / Que con arreglo a las Reales providencias sea la dotación / de dicho maestro de niños de doscientos ducados por este // (179. iruntzia or.) ministerio pagadero de tres en tres meses por el tesorero / de propios de la 
villa y mas cien ducados por razon de / organista pagadero en igual forma de efectos de la fa / brica de la iglesia de modo que en todo tenga trescientos / ducados anuales de sala rio estando viudas a mbas plazas / con arreglo a dichas Reales Ordenes. / Que a mas de dicha dotación señalan tambien para habitación / de dicho Asurmendi la casa contigua a la sala cofradial esto es / el poder habita r en ella sin tener que pagar renta reserban /dose el dominio voz y voto para la villa y el poder poner in / quilino caso de no habita rla por si el maestro quien / como quiera que sea ha de tener la escuela precisamente / en dicha sa la cofradial de la villa. /Que cumpliendo exactamente con su obliga ción no se moleste a un / quando espiren los nueve a ños por los que se otorga esta escritura / pero no tenga efecto esta a un para el termino señalado fal / tando dicho Asurmendi con las obligaciones que le son impuestas. / Que mayor firmeza y estabilidad de esta escritura se solicite en el / Real Consejo su aprobación y de todo lo estipulado con vista de los / antecedentes y con arreglo a dichas Reales Ordenes. / Y dichos señores capitulares y comisionados del Ayuntamiento / en representa ción de esta referida villa digeron que recibian / por tal maestro de primera letras y organista de dicha / parroquial al referido don Jose Joaquin de Asurmendi vajo las / calidades ca rga sobliga ciones y condiciones suso expre / sa da s para tiempo y espacio del año proximo de noventa y dos // (180. aldea or.) obligándose en legal forma en quanto pueden y de derecho / ha lugar a satisfacerle por razon de dichos dos empleos es a sa / ver esta enunciada villa doscientos ducados y la fabrica /otros cien ducados de tres en tres meses y a mas la libartad / de poder habitar en la casa contigua a la sa la cofradial /vajo los requisitos expresados y con que cumpla las con / diciones le sera cierta y segura esta escritura a cuia observancia /obligan a dicha villa y en calidad de patronos la fabrica de dicha iglesia /vajo la pena de ejecución a premio y costas según mejor puedan / y ha lugar en derecho. Ya fin de obtener la aprobación y confir / macion de la misma escritura otorgan que dan su poder cumplido / el que se requiere y es necesa rio a don Felipe Francisco de Avira neta / agente de negocios vecino de la corte de Madrid especialmente / para que en representación de esta villa obtenga en el / Real y Supremo Consejo de Castilla o donde corresponda la / aprobación de esta escritura haciendo para el efecto las instancias / necesarias con presentación de documentos y doto lo de / mas que harian o hacer podrían los otorgantes pues por / el efecto le confieren el mas a mplio poder con libre / franca y general administración sin limitación y / facultad de substituir en quien y las veces que le pa / reciere revocar los vnos substitutos y nombrar /otros obliga ndo los propios de dicha villa y siendo / necesa rio sus personas y bienes a tener por (IRAKURGAITZA) por dicho Avira neta y sus substitutos (IRAKURGAITZA) // (180. iruntzia or.) el referido don Jose Joaquin de Asurmendi enterado de la / escritura precedente y condiciones que dijo que a ceptaba / y se obligaba con su persona y bienes muebles y raices / habidos y por haber a la puntual observancia y entero cum / plimiento de quanto se expresa para lo qual las daba aquí por / expresas y repetidas sin que en contrario de lo expresado pueda / alegar la menor cosa pena de ser castigado por todo rigor de derecho. / Y todas la dichas partes se obligan al cumplimiento de lo que a cada / vno toca y dan poder bastante a los señores jueces y justicias / de ser para que a ello le a premien por todo rigor via ejecutiva / como por sentencia pasada en a utoridad de cosa juzgada / renunciaron todas la sleyes del caso con las de minoridad / beneficio de restitución que competen a la referida villa / y la fabrica de su iglesia en toda forma y a si lo otorgan siendo testigos Tomas de Imaz Jose Antonio de Zufiria y Francisco de / Zubiza rreta vecinos de esta villa. E yo el escriba no doy fe conozco / a los o torgantes firma ron los que saben y por los que /digeron no saber lo hizo vno de dichos testigos. / Joaquin Thomas de Beguirista in (SINADURA) / Pedro Antonio de Aierdi (SINADURA) /Juan Antonio de Muxica (SINADURA) / Jose Joaquin de Asurmendi (SINADURA) / Tomas de Imaz (SINADURA) / Ante mi / Luis Ignacio de Barandiaran (SINADURA).

Gipuzkoako Agiritegi Orokorra, PT IPT 1945, 178. al. or.- 181. al. or.) 